\title{
Electronic Diary: Assessment, Current Condition and Implementation of Application
}

\author{
Sumayya Afreen, Amtul Sana Amreen, Khutaija Abid, Syed Ahmeduddin
}

\begin{abstract}
The latest technological boom has moved the area of recorded medical results (PROs) into a new age. Using a very good user interface the application e-Diary is used to record your diary electronically. This application is used not only for managing your diary but also for managing your favorite songs, videos, websites, contacts and events.. In this paper we will also show the implementation of Application of Electronic Diary.
\end{abstract}

Keywords: Ecological Momentary Assessment, Electronic Diary.

\section{INTRODUCTION}

Electronic Diaries is a way to have a replica of a journal on your screen. It allows people to search their appointments and to label appointments on online "regular pages." Because the machine keeps the specifics of every consumer schedule, meetings and conferences will be recorded in advance. Software use often brings versatility into the diary style, offering various perspectives, such as year, month, or week. In comparison to a paper journal, as required, the machine automatically inserts fresh sheets, extra space for each day, and preserves copies of diaries for years gone by. While this is useful, an electronic diary has the most important advantage over a paper one in its ability to be shared. Contemporary core of diaries go back to at least the early part of the 20th century as a form of data collection. In order to better understand the etiology and course of symptoms, patients were asked to keep an ongoing record of symptoms that could be reviewed by the physician.[1] However, it was not until later in the century that the method gained scientific attention.

\section{CONVENTIONAL SELF-REPORT QUESTIONNAIRES VERSUS MOMENTARY ASSESSMENT}

Traditional baseline and post-treatment assessment of symptom severity with a questionnaire is by far the easiest from a practical and economic point of view. Many selfreporting instruments have a long history of use in clinical trials, and associated data with good reliability and validity. They are inexpensive for use by the investigator and imply minimal burden on the patient.

Revised Manuscript Received on August 15, 2020.

* Correspondence Author

Sumayya Afreen*, Assistant Professor, Department of Computer Science and Engineering, Stanley College of Engineering \& Technology, Hyderabad, Telangana, India.

Amtul Sana Amreen, Assistant Professor, Department of Computer Science and Engineering, Stanley College of Engineering \& Technology, Hyderabad, Telangana, India.

Khutaija Abid, Assistant Professor, Lords Institute of Engineering and Technology, Hyderabad, Telangana, India.

Syed Ahmeduddin, Assistant Professor, Lords Institute of Engineering and Technology, Hyderabad, Telangana, India.

(C) The Authors. Published by Blue Eyes Intelligence Engineering and Sciences Publication (BEIESP). This is an open access article under the CC BY-NC-ND license (http://creativecommons.org/licenses/by-nc-nd/4.0/)
Why, then, was there a movement towards more burdensome diaries?

\section{EXISTING SCHEME}

All functions such as allowing e-diary, arranging meetings, activities , personal records, favourite blogs, music, videos are all distributed through different apps within the current program. There are still some applications which simulate these features in an e-way. All these features are integrated in this application and all those can be easily scheduled in any way the user wants.

\section{PLANNED SYSTEM}

The program suggested allows for the customer to manage timetable, contact Policy, timing activities, and hold favorites

\section{ARCHITECTURE}

This application is based on three-tiered architecture. The three structures are Presentation tier, Application Level, Data Tier

\section{A. Presentation Tier}

This is the application 's tallest point. The overview rate shows information pertaining to items such as product searching, ordering and contents of shopping carts. It connects with other third parties via the processing of data to the browser / client tier and all other network thirds.

\section{B. Application Tier (company / logic level)}

As its own row, the logic tier is taken out of the presentation tier and. It manages the performance of an application by doing thorough analysis.

\section{Data Tier}

This tier consists of servers for databases. Data is saved and collected here. This rate holds data impartial and separate from business logic or device servers. Giving data its own tier also increases accuracy and scalability.

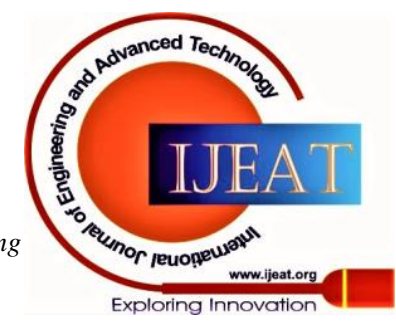


Electronic Diary: Assessment, Current Condition and Implementation of Application

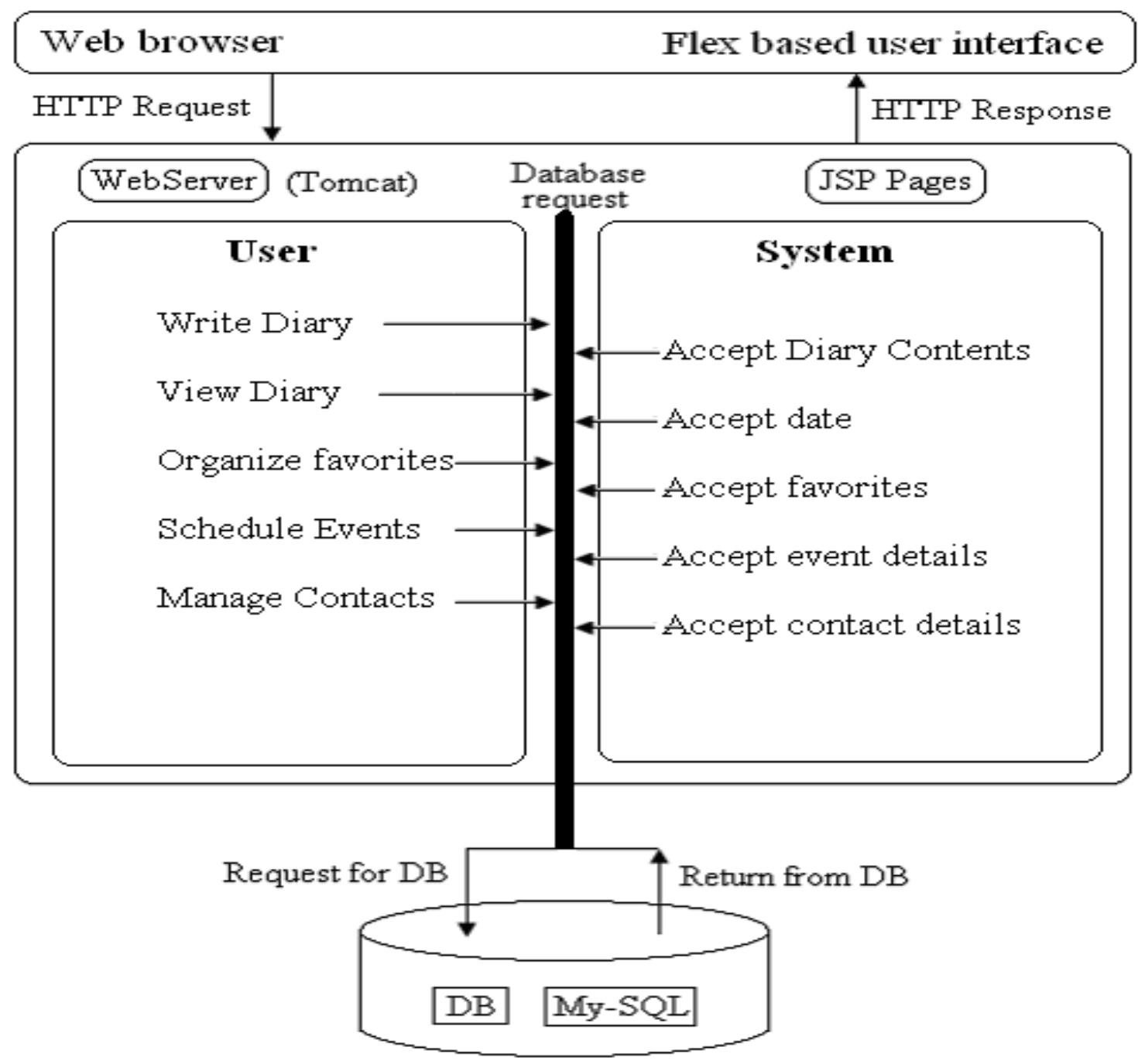

VI. SERVER GROWTH

Database design is the process by which a comprehensive database model is created. This logical data model includes all the required choices in conceptual and physical architecture and the physical storage parameters needed to produce a specification in a Computer Description Format, which can then be used to construct a database. A professionally delegated layout of the data includes specific attributes for each person.

\section{A. Database Tables}

\section{Contacts}

This table is used to store contacts details

\begin{tabular}{|l|l|l|l|}
\hline Fields & Data Type & Size & Constraints \\
\hline Id & Varchar2 & 20 & Primary Key, Auto increment \\
\hline Name & Varchar2 & 50 & not null \\
\hline Home phone & Varchar2 & 10 & not null \\
\hline Personal phone & Varchar2 & 10 & not null \\
\hline Office phone & Number & 10 & not null \\
\hline Address & varchar & 50 & not null \\
\hline Mailid & varchar & 35 & not null \\
\hline
\end{tabular}

Videos

This table is used to store the details of videos

\begin{tabular}{|l|l|l|l|}
\hline Fields & Data Type & Size & Constraints \\
\hline Id & Int & 20 & Primary Key \\
\hline Path & Varchar2 & 70 & not null \\
\hline
\end{tabular}




\section{Electronic Diary: Assessment, Current Condition and Implementation of Application}

Music

This table is used to store the details of Music.

\begin{tabular}{|l|l|l|l|}
\hline Fields & Data Type & Size & Constraints \\
\hline Id & Int & 20 & Primary Key \\
\hline Path & Varchar2 & 70 & not null \\
\hline
\end{tabular}

Diary

This table is used to store the details daily diary.

\begin{tabular}{|l|l|l|l|}
\hline Fields & Data Type & Size & Constraints \\
\hline Date & Int & 2 & Primary key \\
\hline Month & Int & 2 & Primary key \\
\hline Year & Int & 4 & Primary Key \\
\hline Content & Varchar2 & 50 & not null \\
\hline
\end{tabular}

\section{Events}

This table is used to store the details the events.

\begin{tabular}{|l|l|l|l|}
\hline Fields & Data Type & Size & Constraints \\
\hline Date & Int & 2 & Primary key \\
\hline Month & Int & 2 & Primary key \\
\hline Year & Int & 4 & Primary Key \\
\hline Hours & Int & 2 & not null \\
\hline Minutes & Int & 2 & not null \\
\hline To do & Varchar & 50 & not null \\
\hline
\end{tabular}

\section{TEST CASES}

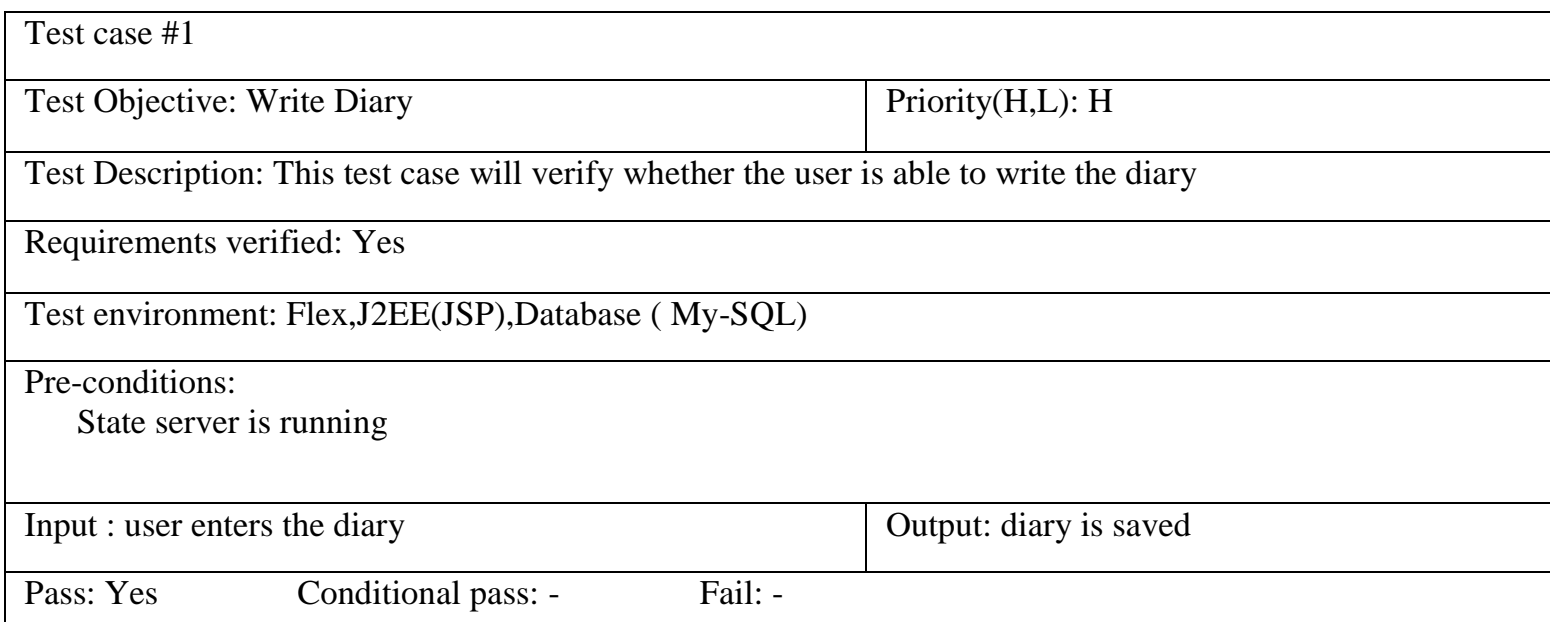

\begin{tabular}{|l|l|}
\hline Test case \# 2 & Priority(H,L): H \\
\hline Test Objective: View Diary & \\
\hline Test Description: This test case will verify whether the user is able to view his previous diary \\
\hline Requirements verified: Yes \\
\hline Test environment: Flex,J2EE(JSP),Database( My-SQL) \\
\hline $\begin{array}{l}\text { Pre-conditions: } \\
\text { State of server is running }\end{array}$ \\
\hline \begin{tabular}{l} 
Input : Valid details are entered in all fields Conditional pass:- \\
\hline Pass: Yes Fail:-
\end{tabular} \\
\hline
\end{tabular}




\begin{tabular}{|c|c|}
\hline \multicolumn{2}{|l|}{ Test case \# 3} \\
\hline Test Objective: Organize videos & Priority(H,L): $\mathrm{H}$ \\
\hline \multicolumn{2}{|c|}{ Test Description: This test case will verify whether the user is able to organize his videos } \\
\hline \multicolumn{2}{|c|}{ Requirements verified: Yes } \\
\hline \multicolumn{2}{|c|}{ Test environment: Flex,J2EE(JSP),Database( My-SQL) } \\
\hline \multicolumn{2}{|c|}{$\begin{array}{l}\text { Pre-conditions: } \\
\text { State of server is running }\end{array}$} \\
\hline Input: path of the video & Expected results: video path is stored \\
\hline Pass: Yes $\quad$ Conditional pass:- & \\
\hline
\end{tabular}

\begin{tabular}{|c|c|}
\hline \multicolumn{2}{|l|}{ Test case \# 4} \\
\hline Test Objective: Organize music & Priority(H,L): H \\
\hline \multicolumn{2}{|c|}{ Test Description: This test case will verify whether the user is able to organize his music } \\
\hline \multicolumn{2}{|c|}{ Requirements verified: Yes } \\
\hline \multicolumn{2}{|c|}{ Test environment: Flex,J2EE(JSP),Database( My-SQL) } \\
\hline \multicolumn{2}{|c|}{$\begin{array}{l}\text { Pre-conditions: } \\
\quad \text { State of server is running }\end{array}$} \\
\hline Input: path of the music & Expected results: music path is stored \\
\hline Conditional pass:- & iil:- \\
\hline
\end{tabular}

\begin{tabular}{|l|l|}
\hline \multicolumn{2}{|l|}{ Test case \#5: } \\
\hline Test Objective: store contacts & Priority(H, L): H \\
\hline Test Description: This test case will verify whether the contacts are stored \\
\hline Requirements verified: Yes \\
\hline Test environment: Flex,J2EE(JSP),Database( My-SQL) \\
\hline Pre-conditions : State of server is running \\
\hline Input: The user enters the contact details \\
\hline Pass: Yes Conditional pass:- \\
\hline
\end{tabular}

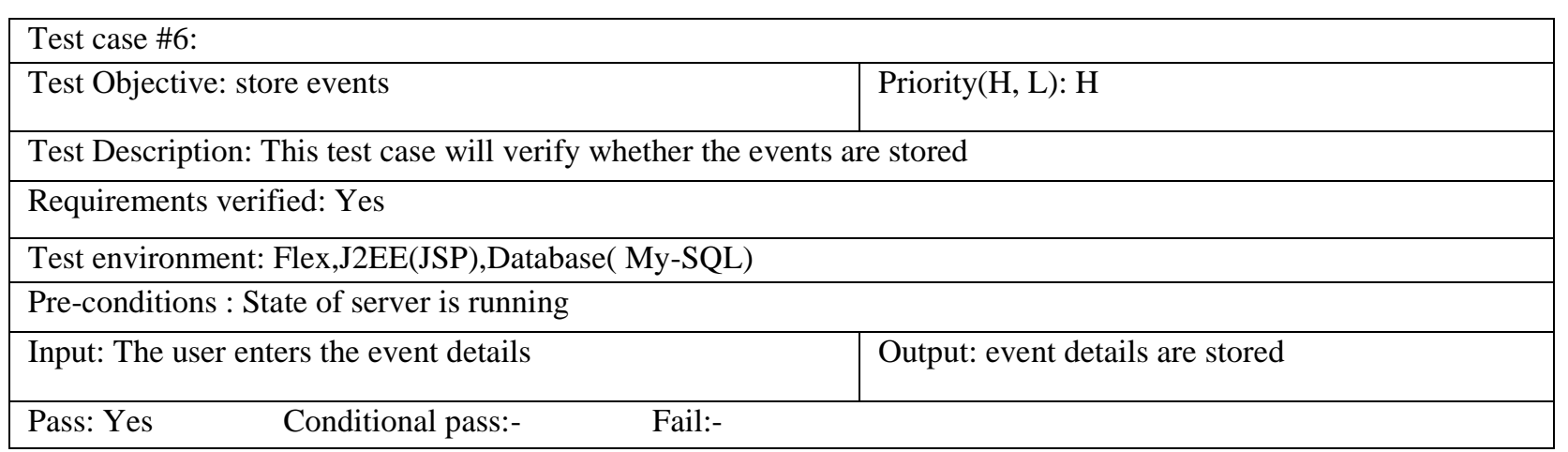


Electronic Diary: Assessment, Current Condition and Implementation of Application

\section{IMPLEMENTATION}

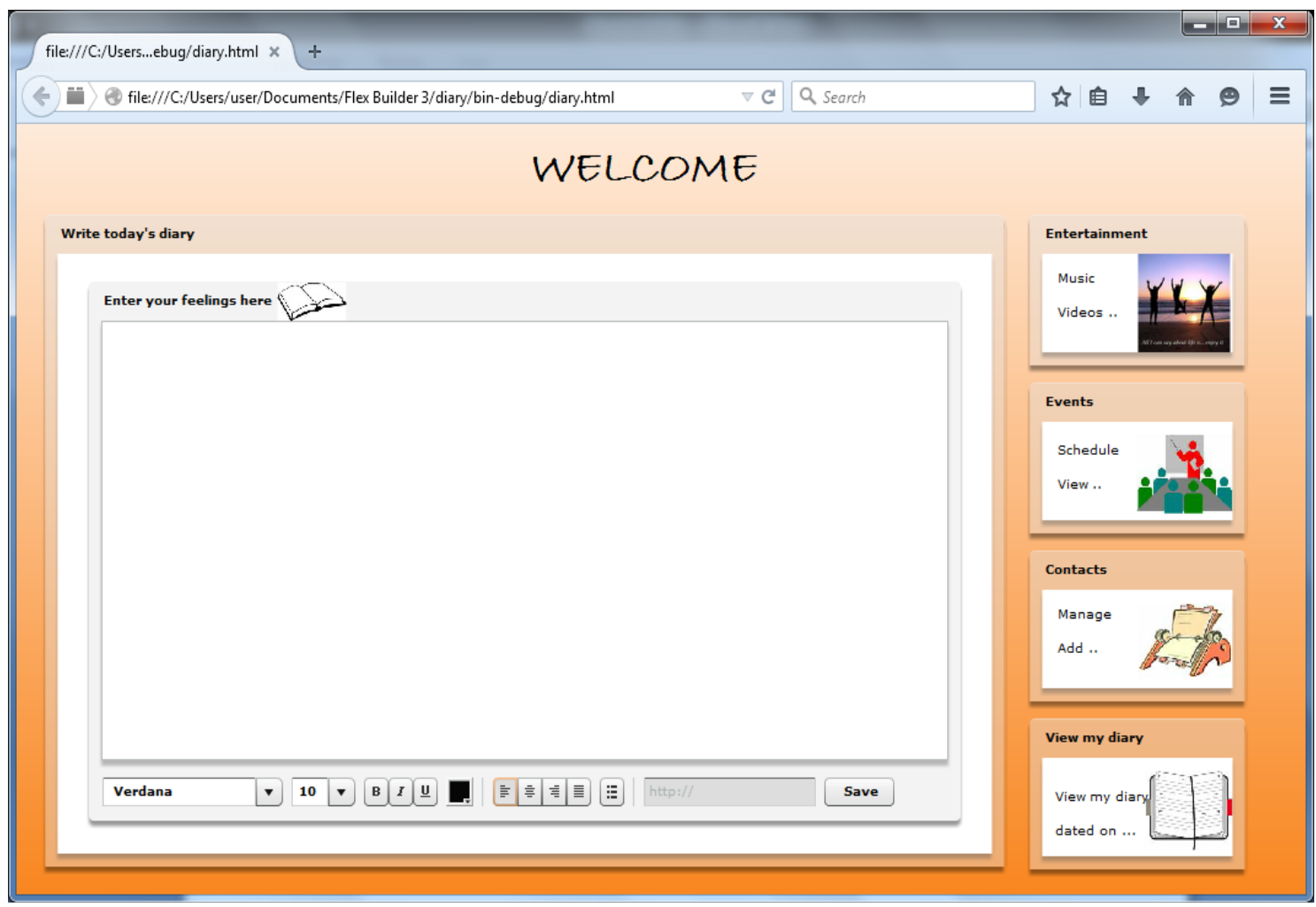

Fig 1. Screen to write diary

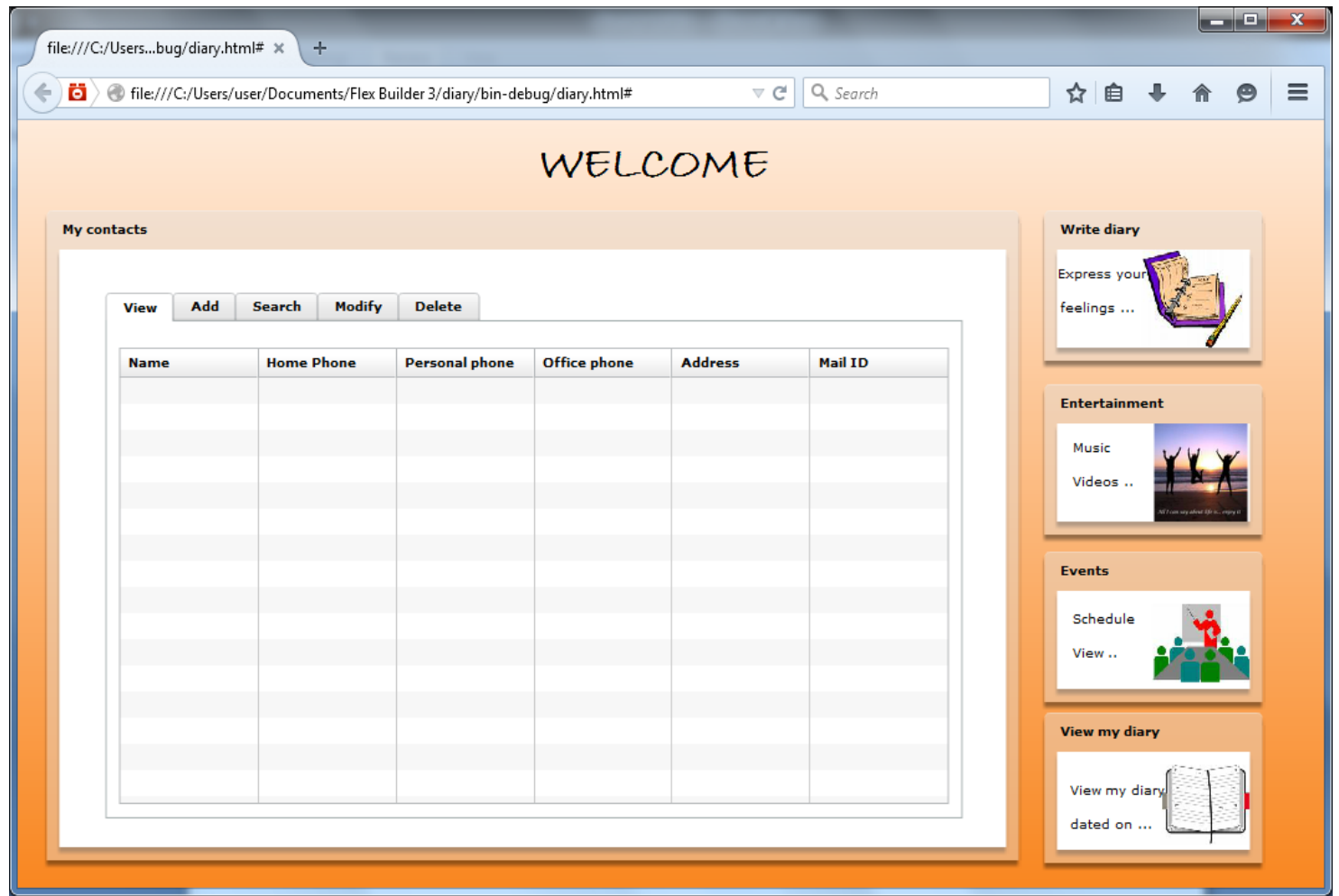

Fig 2. Screen for using Contacts

Published By:

Blue Eyes Intelligence Engineering

and Sciences Publication

(c) Copyright: All rights reserved.

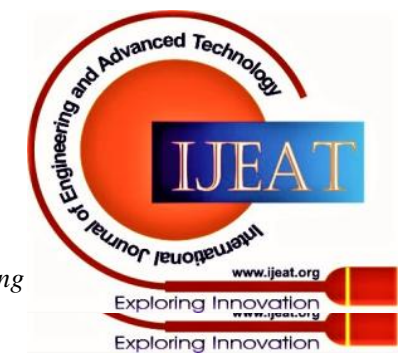




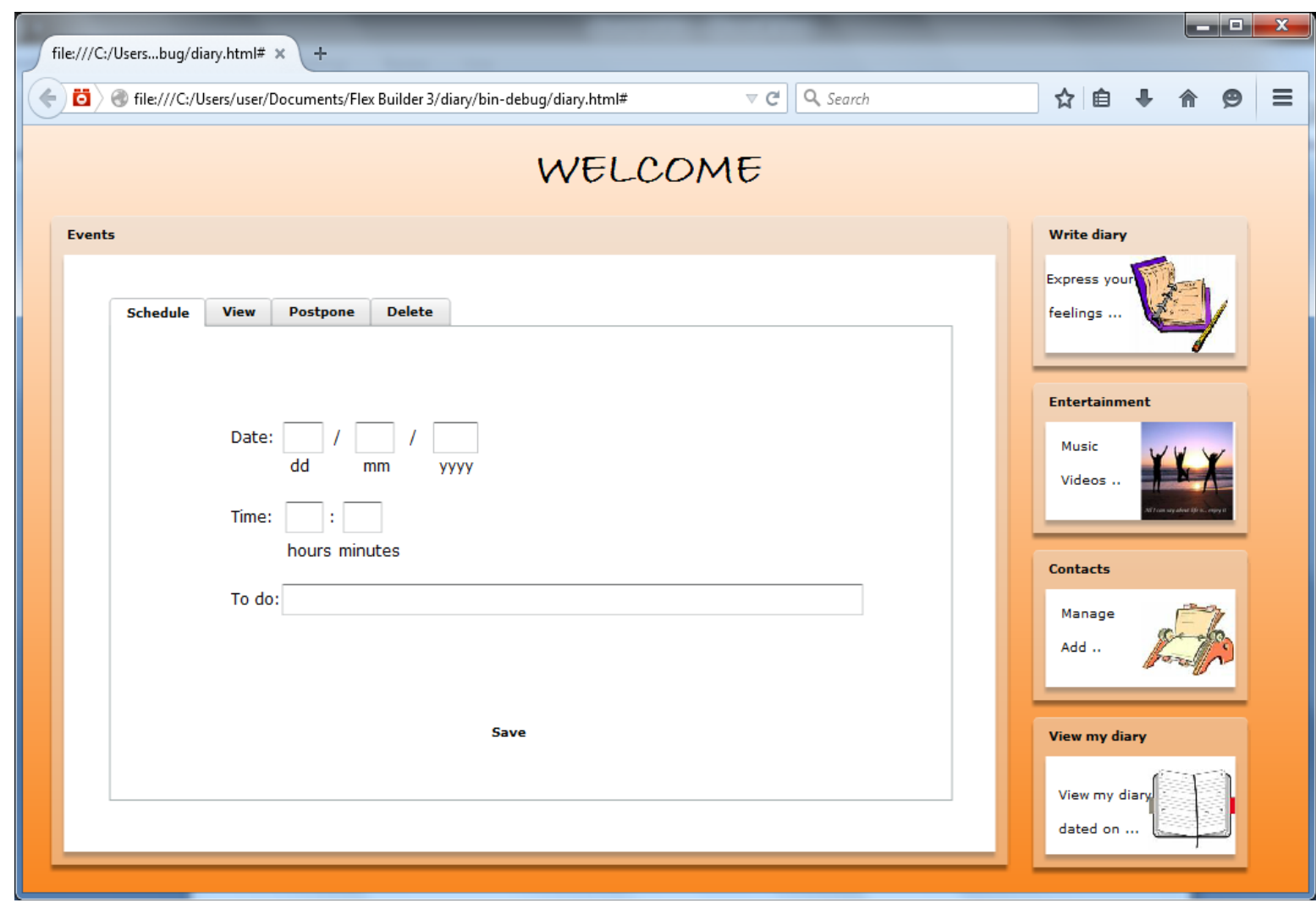

Fig 3. Screen for using Events

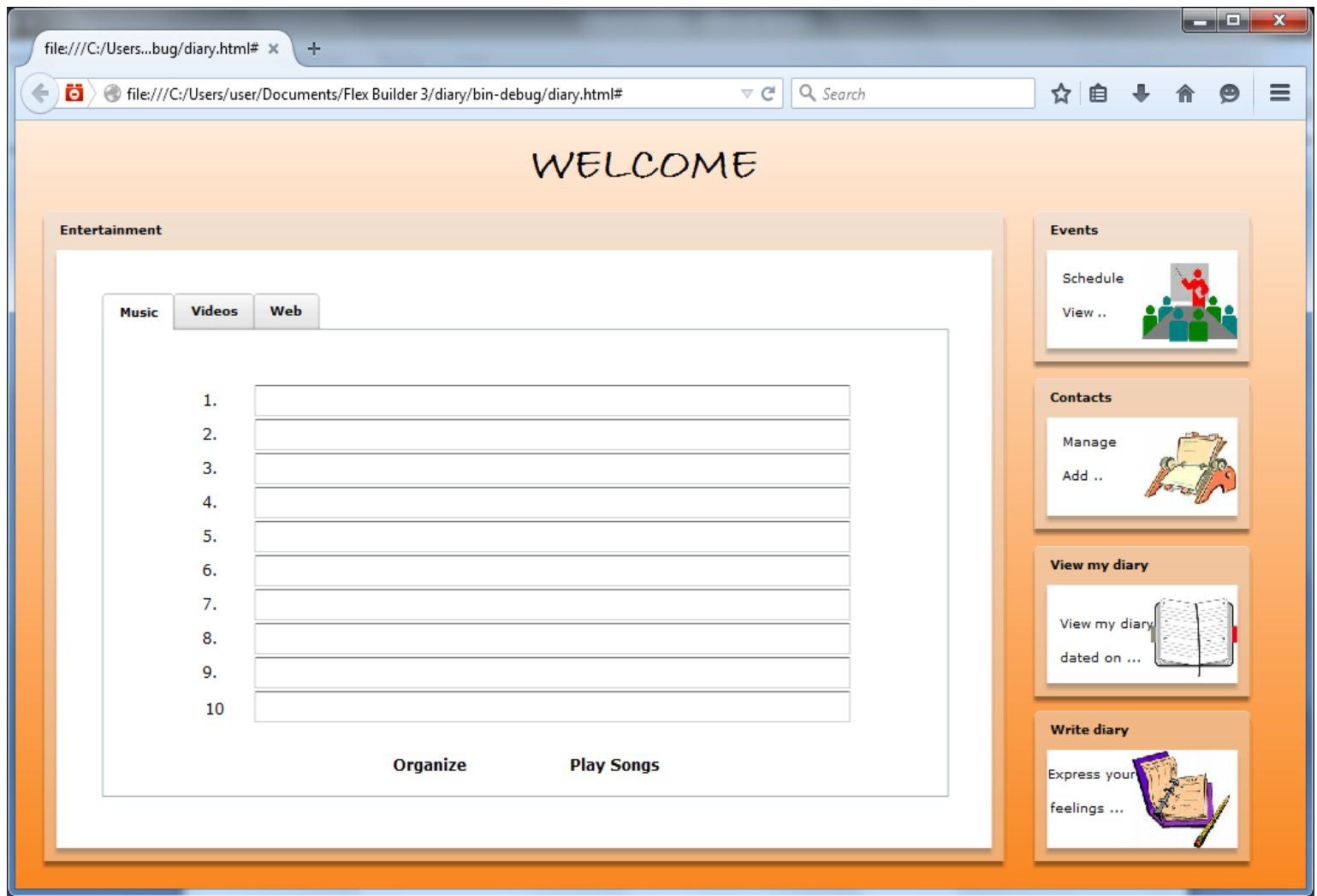

Fig 4. Screen for using Entertainment

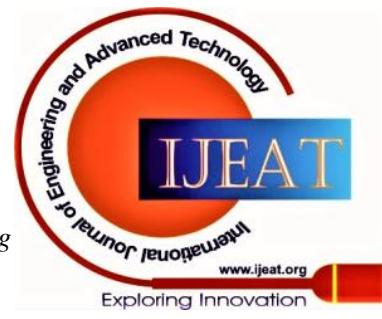




\section{Electronic Diary: Assessment, Current Condition and Implementation of Application}

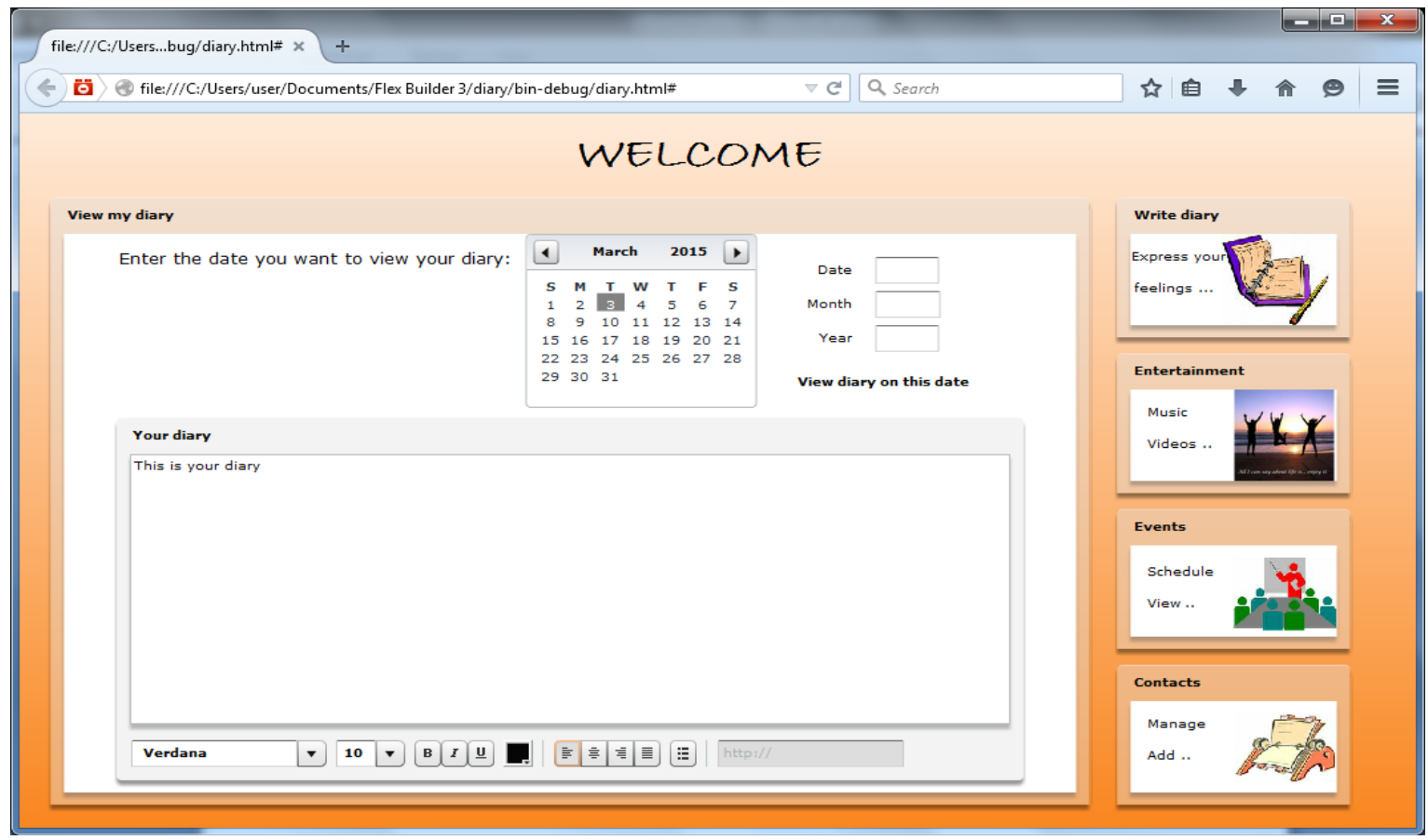

Fig 5. Screen to view diary on a given date

\section{CONCLUSION}

The topic of data interpretation is another essential concern for studies that use diaries that produce multiple in-person measurements. While creating a single mean rating for the reporting period may be appropriate to aggregate across ratings in some cases, in many cases the complexity of the data issues will dictate a more sophisticated approach using multi-level modeling. Several evaluations of these measures are available.[42,49,50] In view of the multiple ratings provided by diaries, it is possible to analyze the durability of the system being evaluated and the volatility over time in ways not available in the conventional single-point assessment process.

\section{REFERENCES:-}

1. Csikszentmihalyi M, Larsen R. Experience-Sampling Method Validity and Reliability. 1987 Journal of Emotional and Behavioral Illness;175:526-36. [MedPub: 3655778]

2. Favill D, Rennick CF. A family case of periodic paralysis. The Neurology and Psychiatry Archives1924;11:674-9.

3. Delespaul P, De Vries MW. Everyday life of psychiatric mental illness of outpatients. Journal of Nervous\& Mental Disease 1987;175(9):537-44. [MedPub: 3655779]

4. Barker, R. Landscapes, climates, and human behaviour: Midwest Psychiatric Field Station experiments in evolutionary psychology and ecobehavioral science: 1947-1972. SanFrancisco: Jossey-Bass; 1978.

5. Stone AA, Reed BR, Neale JM. Shifts in duration of daily occurrenceY Precede actual symptomatic episodes. Journal of the Summer of Human Stress; 1987 13(2):70-4. [MedPub: 3611753]

6. Stone AA, Neale JM. Effects on mood from severe everyday events. Personality and Social-Psychology Journal Jan;1984 46(1):137-44. [MedPub: 6694057]

7. Stone A, Shiffman S. Momentary Ecological Assessment (EMA) in conduct medicine. 1994;16:199-202.

8. Annals of Behavioral Medicine. Bradburn N, Rips L, Shevell S. Replying to autobiographical questions: the effect on polls of recollection and inference. Science 1987;236:157-61. [MedPub: 3563494]

9. Schwarz, N. Self-reporting retrospective and concurrent: The rationale for data capture in real time. In: Stone, AA.; Shiffman, S. Atienza, AA.Publishers. Real-time data collecting science. Oxford University Press; New York: 2007.

10. Gorin, A.A.; Stone, A.A. In retrospective self-reports, recall biases and cognitive errors: A call for momentary assessment. In: Baum, A.;
Revenson, T.; Editors: Singer, J. HealthPsychology handbook. Mahwah, N.J.: 2001. Line 405-13.

11. Robinson M, Clore G. In emotional self-report, episodic and semantic knowledge: evidence for two processes of judgment. Journal of Social Psychology and Personality 2002;83:198-215. [MedPub:12088126]

12. Stone AA, Broderick JE, Schwartz JE, Shiffman S, Litcher-Kelly L, Calvanese P. Recording discomfort intensively in an online diary: reactivity, compliance, and Patient. Pain Jul;2003 104(12):343-51.

\section{AUTHORS PROFILE}

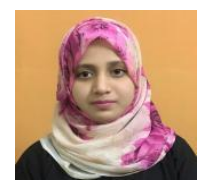

Sumayya Afreen, is a Ph.D scholar from Osmania University, and working as Assistant professor at Stanley College of Engineering \& Technology for Women from 7 years. She has Bachelors Degree in Computer Science and Engineering and Masters Degree in Software Engineering. Her area of interest is Cloud computing, Edge Computing and IoT, in which she has published many research papers.

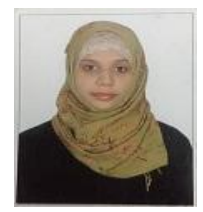

Amtul Sana Amreen, is a Ph.D scholar from KL University, and working as Assistant professor at Stanley College of Engineering \& Technology for Women. She has Bachelors Degree and Masters Degree in Computer Science and Engineering. Her area of interest is Cloud computing, IoT and Machine Learning, in which she has published many research papers.

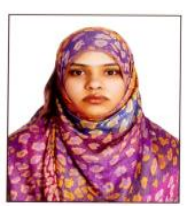

Khutaija Abid, has been in the teaching profession for about 7 years, and joined as an Assistant Professor in Lords Institute of engineering and technology in 2019. She received her M.tech degree in 2013 from LIET, Telangana. Her area of interest is Network Security, Programming languages and Computer Network.

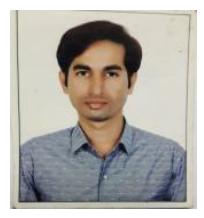

Syed Ahmeduddin, has been in the teaching profession for about 7 years, and joined as an Assistan Professor in Lords Institute of Engineering and Technology in 2019. He received his M.Tech degree in 2014 from SRTIST, Nalgonda. His area of interest is Computer networks, Network security and Operating systems.

Published By:

Blue Eyes Intelligence Engineering

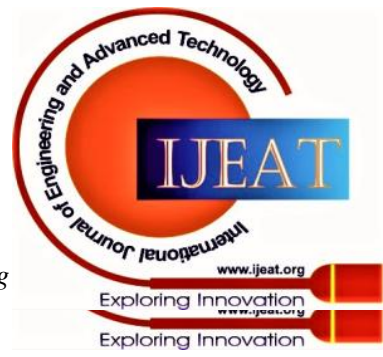

